\title{
FAKTOR-FAKTOR YANG MEMPENGARUHI KUALITAS INFORMASI LAPORAN KEUANGAN PEMERINTAH DAERAH
}

(Studi Empiris pada OPD Kabupaten Gunungkidul)

\author{
Vidya Vitta Adhivinna, Ariyanti Nurul Hikmahwati, \\ Program Sarjana Akuntansi, Fakultas Bisnis, Universitas PGRI Yogyakarta \\ adhivinna@upy.ac.id \\ nurulhikmahwati25@gmail.com
}

\begin{abstract}
This study aims to examine the effect of competency of human resources, utilization of information technology, government internal control system, and regional financial accounting system on the information quality of local government financial statement.

Data was collected by distributing questionnaires to 28 regional government organization of Gunungkidul Regency. Sampling using a Purposive Sampling technique with criteria is employees who work in the accounting or financial administration with respondents are 72 people. Data were analyzed using SPSS program version 16 and hypothesis testing using multiple linear regression analysis.

The results showed that partially, human resource competency, utilization of information technology and government internal control system did not affect the information quality of local government financial statement, while the regional financial accounting system affected the information quality of local government financial statement. Simultaneously, HR competency, utilization of IT, government internal control system, and regional financial accounting system affect the information quality of local government financial statement.
\end{abstract}

Keywords: information quality of local government financial statement, human resource competency, utilization of IT, government internal control system, and regional financial accounting system.

\section{ABSTRAK}

Penelitian bertujuan untuk mengetahui faktor-faktor yang mempengaruhi kualitas informasi laporan keuangan pemerintah daerah. Penelitian ini menggunakan variabel kompetensi SDM, pemanfaatan TI, SPIP, dan SAKD terhadap kualitas informasi LKPD.

Data diperoleh melalui penyebaran kuesioner kepada 28 OPD Kabupaten Gunungkidul. Sampel diambil dengan teknik Purposive Sampling, kriterianya adalah pegawai yang bekerja di bagian akuntansi atau penatausahaan keuangan dengan responden sebanyak 72 orang. Data dianalisis menggunakan progam SPSS versi 16 dan uji hipotesis menggunakan analisis regresi linear berganda

Hasil penelitian menunjukkan secara parsial, kompetensi SDM, pemanfaatan TI dan SPIP tidak memiliki pengaruh terhadap kualitas informasi LKPD, sementara SAKD berpengaruh terhadap kualitas informasi LKPD. Secara simultan, kompetensi SDM, pemanfaatan TI, SPIP, dan SAKD memiliki pengaruh terhadap kualitas informasi LKPD.

Kata kunci : kualitas informasi laporan keuangan pemerintah daerah, kompetensi SDM, pemanfaatan $\mathrm{TI}$, sistem pengendalian intern pemerintah, dan sistem akuntansi keuangan daerah.

\section{PENDAHULUAN}

Pemerintah daerah akan mampu mewujudkan transparansi dan akuntabilitas, bila informasi yang ada dalam LKPD sesuai dengan kriteria karakteristik kualitatif laporan keuangan yang mengacu pada PP No 71 Tahun 2010 (Rahmawati dkk, 2018). Berdasarkan data dari IHPS I tahun 2018 BPK RI, Kabupaten Gunungkidul mengalami peningkatan opini dari tahun 2014 menuju 2015. Tahun 2014 diperoleh opini Wajar Dengan Pengecualian (WDP), kemudian tahun 2015 - 2017 memperoleh opini Wajar Tanpa Pengecualian (WTP). Pencapaian opini WTP menunjukkan bahwa penyajian dan pengungkapan LKPD Kabupaten Gunungkidul adalah wajar. 
Upaya untuk mewujudkan good governance harus diimbangi dengan SDM yang kompeten dalam mengelola keuangan daerah. Telah menjadi permasalahan umum di instansi pemerintah daerah, dalam penataan personilnya yang tidak sesuai dengan kebutuhan baik secara kuantitas maupun kualitas (Inapty dan Martiningsih, 2016). Pegawai dengan latar belakang pendidikan akuntansi yang terbatas, menjadikan kurangnya pemahaman atau kemampuan dalam pengelolaan keuangan yang benar (Andini dan Yusrawati, 2015).

Pemerintah Daerah melalui PP No 65 tahun 2010 diwajibkan untuk melakukan pengembangan dan pemanfaatan kecanggihan $\mathrm{TI}$ untuk meningkatkan pengelolaan keuangan daerah serta menyediakan informasi keuangan kepada pelayanan publik (Rahmadani, 2015). Namun, jika pemanfaatan teknologi informasi tidak mampu atau belum optimal, penerapan teknologi akan menjadi sia-sia dan mahal, karena membutuhkan biaya banyak (Wansyah dkk, 2012).

Sistem Pengendalian Intern (SPI) berfungsi untuk memberi keyakinan memadai atas terwujudnya efektifitas dan efisiensi proses akuntansi terlebih dalam menghasilkan informasi laporan keuangan yang andal. Reliabilitas, objektivitas informasi

\section{LANDASAN TEORI}

Laporan keuangan sektor publik yaitu representasi posisi keuangan dari aktivitas transaksi entitas sektor publik. Pelaporan keuangan bertujuan umum menyediakan informasi posisi keuangan, kinerja, dan arus kas yang digunakan oleh sebagian besar pemakai untuk mengambil dan menilai keputusan terkaitalokasi sumber daya yang digunakan entitas dalam aktivitasnya untuk mencapai tujuan (Bastian, 2015).

Kompetensi merupakan kemampuan dan karakteristik yang dimiliki oleh PNS, berwujud pengetahuan, keterampilan dan sikap perilaku yang diperlukan dalam pelaksanaan tugas jabatannya, sehingga PNS dapat melaksanakan tugasnya secara profesional, efektif dan efisien (Permendagri No 2 Th 2013). dapat ditingkatkan dengan SPI dan SPI mampu mencegah ketidakkonsistenan serta proses audit laporan keuangan menjadi mudah (Mahaputra dan Putra, 2014). Kabupaten Gunungkidul memperoleh nilai 3,08 atau berada di tingkat 4 (terdefinisi) yang artinya praktik pengendalian intern di Pemerintah daerah Kabupaten Gunungkidul telah dilaksanakan dan terdokumentasi dengan baik, namun pengendalian intern dievaluasi tanpa dokumentasi yang memadai. Nilai yang diperoleh Kabupaten Gunungkidul menempati urutan terbawah di wilayah DIY (Lap. Hasil Pengawasan atas Akuntabilitas Keuangan Negara/Daerah Tahun 2017 BPKP DIY).

LKPD dihasilkan oleh SAKD. Secara konsep, penerapan sistem akuntansi yang baik, akan menghasilkan LKPD yang berkualitas ditandai dengan minimalnya kesalahan pencatatan, kecurangan, ketidakpatuhan pada hukum dan diwujudkan dengan opini dari BPK serta memenuhi karakteristik kualitatif informasi laporan keuangan (Patra dkk, 2015).

Penelitian ini adalah replikasi penelitian Nurillah (2014). Perbedaan hasil penelitian terdahulu membuat peneliti tertarik untuk meneliti kembali pengaruh kompetensi SDM, pemanfaatan TI, SPIP, dan SAKD.

Komputer, software, basis data, dan jenis lainnya termasuk dalam teknologi informasi. Tladalah teknologi yang dimanfaatkan untuk pengelolaan data, termasuk mendapatkan, pemrosesan, penyusunan, penyimpanan dan pemanipulasian dengan berbagai cara untuk menyediakan informasi yang berkualitas dan strategis untuk pengambilan keputusan (Setyowati dkk, 2016).

"Sistem Pengendalian Intern adalah proses yang integral pada tindakan dan kegiatan yang dilakukan secara terus menerus oleh pimpinan dan seluruh pegawai untuk memberikan keyakinan memadai atas tercapainya tujuan organisasi melalui kegiatan yang efektif dan efisien, keandalan pelaporan keuangan, pengamanan asset negara dan ketaatan terhadap peraturan perundang-undangan". (PP No 60 Th 2008). 
Berdasarkan Permendagri No 59 Th 2007, sistem akuntansi pemerintah daerah merupakan serangkaian prosedur mulai dari proses pengumpulan data, pencatatan, pengikhtisaran, sampai dengan pelaporan

\section{METODE PENELITIAN}

1. Variabel Penelitian

Variabel independen :kompetensi SDM, pemanfaatan TI, SPIP, SAKD. Variabel dependen :kualitas informasi LKPD 2. Metode dan Teknik Pengumpulan Data Populasi :seluruh pegawai OPD Kabupaten Gunungkidul. Sampel diambil dengan teknik purposive sampling. Kriteria (1) Kepala bagian dan staff akuntansi (2) Kepala bagian

\section{HASIL PENELITIAN}

\section{Deskripsi Data}

OPD di Kabupaten Gunungkidul yang menjadi objek penelitian sebanyak 28 OPD yang terdiri dari 2 sekretariat, 1 Inspektorat, 1 Satpol PP, 5 badan dan 19 dinas. Jumlah kuesioner yang disebar 112 keuangan dalam rangka pertanggungjawaban APBD yang dapat dilakukan secara manual atau menggunakan aplikasi dan staff penatausahaan keuangan (3) Minimal menjabat satu tahun. Data diperoleh dengan menyebarkan kuesioner pada 28 OPD Kabupaten Gunungkidul.

Tabel 1 Karakteristik Responden

\begin{tabular}{|c|c|c|c|}
\hline \multicolumn{2}{|c|}{ Data } & $\mathrm{Jml}$ & Presentase \\
\hline \multirow{2}{*}{ Jenis Kelamin } & $\mathrm{L}$ & 28 & $38,89 \%$ \\
\hline & $\mathrm{P}$ & 44 & $61,11 \%$ \\
\hline \multicolumn{2}{|l|}{ Total } & 72 & $100 \%$ \\
\hline \multirow{4}{*}{ Umur } & $20-30$ th & 5 & $6,94 \%$ \\
\hline & $31-40$ th & 20 & $27,78 \%$ \\
\hline & $41-50$ th & 24 & $33,33 \%$ \\
\hline & $>50$ th & 23 & $31,95 \%$ \\
\hline \multicolumn{2}{|l|}{ Total } & 72 & $100 \%$ \\
\hline \multirow{3}{*}{ Lama Waktu Kerja } & $1-5$ th & 14 & $19,45 \%$ \\
\hline & $5-10$ th & 16 & $22,22 \%$ \\
\hline & $>10$ th & 42 & $58,33 \%$ \\
\hline \multicolumn{2}{|l|}{ Total } & 72 & $100 \%$ \\
\hline \multirow{4}{*}{$\begin{array}{l}\text { Tingkat } \\
\text { Pendidikan }\end{array}$} & SMA & 11 & $15,28 \%$ \\
\hline & Diploma & 9 & $12,50 \%$ \\
\hline & S1 & 41 & $56,94 \%$ \\
\hline & S2 & 11 & $15,28 \%$ \\
\hline \multicolumn{2}{|l|}{ Total } & 72 & $100 \%$ \\
\hline \multirow{5}{*}{$\begin{array}{l}\text { Latar Belakang } \\
\text { Pendidikan }\end{array}$} & Akuntansi & 21 & $29,17 \%$ \\
\hline & Manajemen & 8 & $11,11 \%$ \\
\hline & Ekonomi & 13 & $18,05 \%$ \\
\hline & SMA (IPS) & 4 & $5,56 \%$ \\
\hline & Lain-lain & 26 & $36,11 \%$ \\
\hline \multicolumn{2}{|l|}{ Total } & 72 & $100 \%$ \\
\hline
\end{tabular}

Sumber : data primer diolah, 2019

buah (100\%), tidak kembali 8 buah $(7,14 \%)$, kuesioner yang dapat diolah untuk dianalisis 72 buah (64,29\%), sisanya $32(28,57 \%)$ kuesioner tidak dapat diolah. 


\section{Statistik Deskriptif}

Tabel 2 Statistik Deskriptif

\begin{tabular}{|l|c|c|c|c|c|}
\hline \multicolumn{1}{|c|}{ Variabel } & N & Min & Max & Mean & $\begin{array}{c}\text { Std. } \\
\text { Dev }\end{array}$ \\
\hline Kompetensi SDM $\left(\mathrm{X}_{1}\right)$ & 72 & 23 & 35 & 29,58 & 3,029 \\
\hline Pemanfaatan TI $\left(\mathrm{X}_{2}\right)$ & 72 & 24 & 30 & 26,75 & 2,342 \\
\hline SPIP $\left(\mathrm{X}_{3}\right)$ & 72 & 12 & 25 & 21,15 & 2,180 \\
\hline SAKD $\left(\mathrm{X}_{4}\right)$ & 72 & 30 & 40 & 35,10 & 3,255 \\
\hline Kualitas Informasi LKPD $(\mathrm{Y})$ & 72 & 30 & 40 & 34,58 & 3,103 \\
\hline
\end{tabular}

Sumber : data primer dioleh, 2019

\section{Uji Kualitas Data}

Uji validitas menunjukkan bahwa seluruh variabel tingkat signifikasinya< 0,05, artinya dapat dikatakan bahwa semua item pada seluruh variabel adalah valid. Diketahui dari hasil uji reliabilitas

\section{Uji Asumsi Klasik}

a. Uji Multikoloniearitas

Tabel 3 Hasil Uji Multikoloniearitas

\begin{tabular}{|l|c|c|}
\hline \multirow{2}{*}{ Variabel } & \multicolumn{2}{|c|}{$\begin{array}{c}\text { Colleniearity } \\
\text { Statistics }\end{array}$} \\
\cline { 2 - 3 } & Tolerance & VIF \\
\hline $\begin{array}{l}\text { Kompetensi } \\
\text { SDM }\left(\mathrm{X}_{1}\right)\end{array}$ & 0,362 & 2,762 \\
\hline $\begin{array}{l}\text { Pemanfaatan } \\
\text { TI }\left(\mathrm{X}_{2}\right)\end{array}$ & 0,330 & 3,027 \\
\hline SPIP $\left(\mathrm{X}_{3}\right)$ & 0,390 & 2,565 \\
\hline SAKD $\left(\mathrm{X}_{4}\right)$ & 0,265 & 3,770 \\
\hline
\end{tabular}

Sumber : data primer diolah, 2019

b. Uji Heteroskedastisistas

scatterplot

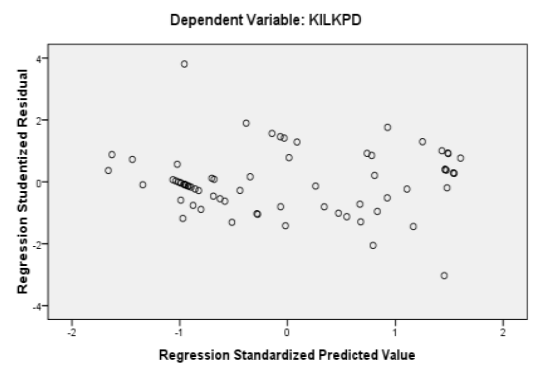

Sumber : data primer diolah, 2019

\section{Gambar 1Hasil Uji}

Heteroskedastisitas

Grafik diatas menunjukkan bahwa penyebaran titik-titik tidak menunjukkan pola yang jelas serta titik-titik tersebar di atas dan di bawah angka 0 pada sumbu $Y$, sehingga bahwa setiap variabel memiliki nilai cronbach alpha $>0,70$, artinya pernyataan pada masing-masing variabel adalah reliabel.

Menurut tabel 3, tidak ada variabel yang memiliki nilai tolerance $<0,1$ dan nilai VIF $>10$, artinya tidak terdapat multikoloniearitas antar variabel bebas pada model regresi.

dapat disimpulkan bahwa dalam model regresi pada penelitian ini tidak terjadi heteroskedastisitas.

c. Uji Normalitas

Normal P-P Plot of Regression Standardized Residual

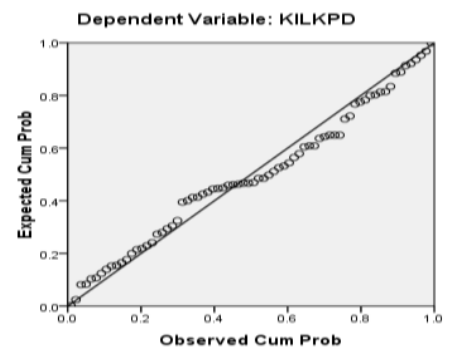

Sumber : data primer diolah, 2019

Gambar 2 Hasil Uji Normalitas (Grafik Normal Probability Plot)

Gambar diatas menunjukkan bahwa pada grafik histogram memberikan 
pola distribusi normal, yaitu tidak menceng ke kanan atau ke kiri. Dilihat dari grafik normal probability plot titik- titiknya menyebar disekitar garis diagonal dan mengikuti arah garis diagonal.

\section{Uji Regresi Linier Berganda}

Tabel 4 Hasil Uji Regresi Linear Berganda

\begin{tabular}{|l|r|r|r|c|}
\hline Variabel & \multicolumn{1}{|c|}{$\mathrm{B}$} & \multicolumn{1}{c|}{$\mathrm{t}$} & \multicolumn{1}{c|}{ Sig. } & Keterangan \\
\hline KSDM & $-0,084$ & $-0,706$ & 0,483 & $\mathrm{H}_{1}:$ Ditolak \\
\hline PTI & 0,056 & 0,349 & 0,728 & $\mathrm{H}_{2}:$ Ditolak \\
\hline SPIP & $-0,018$ & $-0,113$ & 0,910 & $\mathrm{H}_{3}$ : Ditolak \\
\hline SAKD & 0,812 & 6,265 & 0,000 & $\mathrm{H}_{4}$ : Diterima \\
\hline Konstanta & & 7,439 & & \\
Adjusted R & & 0,651 & \\
F & & $34,177($ Sig. $=0,000)$ & $\mathrm{H}_{5}:$ Diterima \\
\hline
\end{tabular}

Sumber : data primer diolah, 2019 Persamaan regresi dapat dirumuskan :

$Y=7,439-0,084 X_{1}+0,056 X_{2}-0,018$

$\mathrm{X}_{3}+0,812 \mathrm{X}_{4}+\mathrm{e}$

Keterangan :

$\mathrm{Y}=$ Kualitas Informasi LKPD

$\mathrm{X}_{1}=$ Kompetensi SDM

$\mathrm{X}_{2}=$ Pemanfaatan $\mathrm{TI}$

$\mathrm{X}_{3}=\mathrm{SPIP}$

$\mathrm{X}_{4}=\mathrm{SAKD}$

Berikut penjelasan mengenai persamaan regresi linear berganda :

1. Konstanta $(\alpha)$ yang diperoleh 7,439 berarti tanpa ada pengaruh dari keempat variabel independen, variabel Kualitas Informasi LKPD sebesar 7,439 satuan.

2. Koefisien Kompetensi SDM $\left(\beta_{1}\right)$ sebesar $-0,084$, berarti apabila terjadi kenaikan nilai variabel Kompetensi SDM sebesar 1 satuan, akan menurunkan Kualitas Informasi LKPD 0,084 satuan atau $8,4 \%$ dengan asumsi variabel lain konstan.

3. Koefisien Pemanfaatan $\mathrm{TI}\left(\beta_{2}\right)$ sebesar 0,056 , artinya apabila terjadi kenaikan variabel Pemanfaatan $\mathrm{TI}$ sebesar 1 satuan, akan menaikkan Kualitas Informasi LKPD 0,056 satuan atau $5,6 \%$ dengan asumsi variabel lain konstan.

4. Koefisien SPIP $\left(\beta_{3}\right)$ sebesar - 0,018, artinya apabila terjadi kenaikan variabel SPIP sebesar 1 satuan, akan menurunkan Kualitas Informasi LKPD 0,018 satuan atau $1,8 \%$ dengan asumsi variabel lain kostan.
5. Koefisien SAKD $\left(\beta_{4}\right)$ sebesar 0,812 , artinya apabila terjadi kenaikan variabel SAKD sebesar 1 satuan, akan menaikkan Kualitas Informasi LKPD 0,812 satuan atau $81,2 \%$ dengan asumsi variabel lain konstan.

6. Uji Koefisien Determinasi $\left(\mathbf{R}^{2}\right)$

Tabel 4 menunjukkan nilai Adjusted $\mathrm{R}^{2}$ sebesar 0,651 , berarti variabel Kualitas Informasi LKPD dapat dijelaskan oleh keempat variabel independen sebanyak $65,1 \%$ dan $34,9 \%$ dijelaskan oleh variabel lain.

7. Uji F

Tabel 4 menunjukkan nilai $F$ hitung 34,177 yang signifikasinya 0,000 atau Sig. $<0,05$, kesimpulannya $\mathrm{H}_{5}$ diterima, yaitu Kompetensi SDM, Pemanfaatan TI, SPIP, dan SAKD secara bersama-sama berpengaruh terhadap Kualitas Informasi LKPD.

8. Uji t

Berdasarkan tabel 4, uji statistik $\mathrm{t}$ dapat dijelaskan sebagai berikut:

1. Kompetensi SDM $\left(X_{1}\right)$ memiliki nilai signifikansi $0,483>0,05$. Artinya $\mathrm{H}_{0}$ diterima dan $\mathrm{H}_{1}$ ditolak.Kesimpulan: Kompetensi SDM tidak memiliki pengaruh terhadap Kualitas Informasi LKPD.

2. Pemanfaatan $\mathrm{TI}\left(\mathrm{X}_{2}\right)$ memiliki nilai signifikansi $0,728>0,05$. Artinya $\mathrm{H}_{0}$ diterima dan $\mathrm{H}_{2}$ ditolak. Kesimpulan: Pemanfaatan TI tidak memiliki pengaruh terhadap Kualitas Informasi LKPD. 
3. SPIP $\left(X_{3}\right)$ memiliki nilai signifikansi $0,910>0,05$. Artinya $\mathrm{H}_{0}$ diterima dan $\mathrm{H}_{3}$ ditolak.

Kesimpulan: SPIP tidak memiliki pengaruh terhadap Kualitas Informasi LKPD.

\section{PEMBAHASAN}

Berdasarkan uji hipotesis variabel kompetensi SDM diketahui bahwa $\mathrm{H}_{0}$ diterima dan $\mathrm{H}_{1}$ ditolak, nilai signifikasinya lebih dari 0,05 , artinya kompetensi SDM tidak memiliki pengaruh terhadap kualitas informasi LKPD Kab Gunungkidul. Dilihat dari data demografi responden, pegawai pengelolan keuangan Kabupaten Gunungkidul sebagian besar merupakan lulusan S1, akan tetapi masih banyak pegawai pengelola keuangan yang berlatar belakang pendidikan bukan akuntansi dan presentasenya terbesar. Penempatan pegawai di pemerintah daerah Kabupaten Gunungkidul, khususnya bagian pengelola keuangan masih belum disesuaikan dengan keahlian setiap individu, tidak semua pengelola keuangan berlatar belakang pendidikan akuntansi menyebabkan kompetensi SDM tidak bepengaruh terhadap kualitas informasi LKPD. Kompetensi SDM tidak memiliki pengaruh terhadap kualitas informasi LKPD juga disebabkan pegawai lebih mengutamakan dalam memanfaatkan TI, yaitu aplikasi SIMDA (Siwambudi, 2017).Penelitian ini sesuai penelitian Inapty dan Martiningsih (2016) yang menerangkan kompetensi aparatur tidak memiliki pengaruh terhadap kualitas informasi laporan keuangan.

Berdasarkan hasil uji hipotesis variabel pemanfaatan TI diketahui bahwa $\mathrm{H}_{0}$ diterima dan $\mathrm{H}_{2}$ ditolak, dimana nilai signifikasinya lebih dari 0,05 , artinya pemanfaatan $\mathrm{TI}$ tidak memiliki pengaruh terhadap kualitas informasi LKPD Kabupaten Gunungkidul. Penyebabnya adalah ketidaksesuaianpenetapan sistem dengan apa yang diinginkan, sistem bermasalah dan penggunanya merasa asing, oleh karena itu pengimplementasian sistem $\mathrm{TI}$ menjadi tidak bermanfaat dan
4. SAKD $\left(\mathrm{X}_{4}\right)$ memiliki nilai signifikansi $0,000<0,05$. Artinya $\mathrm{H}_{0}$ ditolak dan $\mathrm{H}_{5}$ diterima.

Kesimpulan: SAKD berpengaruh terhadap Kualitas Informasi LKPD.

tidakmenunjangkeandalan penyajian laporan keuangan (Surastiani dan Handayani, 2015). Pada kenyataannya pemanfaatan $\mathrm{TI}$ di pemda belum sepenuhnya bisamenambah efektivitas dan efisiensi, memenuhi kebutuhan informasi dan meningkatkan kinerja aparatur pengelola keuangan dalam menyelesaikan pekerjaannya (Setyowati dkk, 2016). Penelitian ini sesuai penelitian Surastiani dan Handayani (2015) yang menerangkanpemanfaatan $\mathrm{TI}$ tidak mempunyai pengaruh terhadap kualitas informasi LKPD.

Berdasarkan hasil uji hipotesis variabel SPIP diketahui bahwa $\mathrm{H}_{0}$ diterima dan $\mathrm{H}_{3}$ ditolak, artinya SPIP tidak mempunyai pengaruh terhadap kualitas informasi LKPD Kabupaten Gunungkidul. Buktinya dengan melihat hasil nilai signifikasinya yang lebih dari 0,05. Penjelasannya, sistem pengendalian internal yang ditetapkan baik, akan tetapi penerapannya masih tidak efektif mengakibatkan laporan keuangan yang dihasilkan informasinya kurang tepat (Yendrawati, 2013). SPIP tidak berpengaruh terhadap kualitas informasi LKPD dikarenakan penyelenggaraan SPIP di Kabupaten Gunungkidul belum efektif dan masih membutuhkan pendampingan. Hal itu sesuai dengan Laporan Hasil Pemeriksaan atas Akuntabilitas Keuangan tahun 2017 bahwa pemda Kab.Gunungkidul telah melaksanakan praktik pengendalian dengan tingkat maturitas berada di tingkat 4 (terdefinisi) dengan skor maturitas 3,08 yang berada di urutan terakhir di Provinsi DIY. Pencapaian itu tidak lepas dari asistensi yang dilakukan oleh BPKP dalam upaya untuk meningkatkan kualitas penyelengaraan SPIP. Penelitian ini sesuai penelitian Yendrawati (2013) dan 
Yensi (2014) yang menerangkan sistem pengendalian intern tidak memiliki pengaruh secara signifikan terhadap kualitas informasi LKPD.

Berdasarkan hasil uji hipotesis variabel SAKD diketahui bahwa $\mathrm{H}_{0}$ dan $\mathrm{H}_{4}$ diterima, dimana nilai signifikasinya kurang dari 0,05, artinya SAKD berpengaruh terhadap kualitas informasi LKPD Kabupaten Gunungkidul. Artinya penerapan SAKD yang semakin tinggi, kualitas laporan keuangan yang dihasilkanakan meningkat. Pemerintah diharuskan untuk menyusun laporan keuangan sesuai dengan SAKD yang diatur pemerintah daerah dan berpedoman pada standar akuntansi pemerintah yang bersifat mengikat, sehingga penerapan SAKD yang baik dan benar berpengaruh terhadap kualitas informasi laporan keuangan pemerintah yang dihasilkan (Mokoginta, 2017).Penelitian sejalan dengan penelitian Andini dan Yusrawati (2015), Rahmadani (2015) dan Alamsyah, dkk (2017) yang menunjukkanSAKD memiliki pengaruh terhadap kualitas LKPD.

Tabel 4 menunjukkan bahwa nilai signifikansi $F$ yaitu dibawah 0,05 , sehingga $\mathrm{H}_{5}$ diterima, artinya kompetensi SDM, pemanfaatan TI, SPIP, dan SAKD secara bersama-sama memiliki pengaruh terhadap kualitas informasi LKPD Kabupaten Gunungkidul. Hasil penelitian ini sejalan dengan penelitian Almasyah, dkk (2017) yang menunjukkankian bertambahnya tinggi kompetensi SDM, pemanfaatan TI, SPIP, dan SAKD, kualitas informasi LKPD akan bertambah baik (Alamsyah dkk, 2017).

\section{PENUTUP}

Kesimpulan

\section{DAFTAR PUSTAKA}

Alamsyah, M R., Rahayu, S., dan Muslih, M. 2017. "Kompetensi Sumber Daya Manusia, Penerapan Sistem Akuntansi Keuangan daerah (SAKD),
Secara parsial kompetensi SDM, pemanfaatan TI dan SPIP tidak memiliki pengaruh terhadap kualitas informasi LKPD Kabupaten Gunungkidul, sedangkan SAKD memiliki pengaruh terhadap kualitas informasi LKPD Kabupaten Gunungkidul. Kompetensi SDM, pemanfaatan TI, SPIP, dan SAKD bersama-sama memiliki pengaruh terhadap kualitas informasi LKPD Kabupaten Gunungkidul.

\section{Saran}

(1) Penelitian selanjutnya diharapkan menambah variabel misalnya komitmen organisasi dan gaya kepemimpinan (2) Penelitian selanjutnya diharapkan menambah metode dengan melakukan wawancara sehingga data yang didapatkan lebih kredibel (3) Data identitas responden dalam kuesioner sebaiknya dibuat secara jelas dengan memberikan kategori di setiap aspek, sehingga didapatkan data responden secara lebih jelas dan akurat.

\section{Implikasi}

1. Pemda Kabupaten Gunungkidul sebaiknya menempatkan pegawai sesuai dengan keahlian dan latar belakang pendidikan masing-masing individu khususnya bagian pengelolaan keuangan agar meningkatkan kompetensi dan kinerja pengelola keuangan OPD.

2. Pemda Kabupaten Gunungkidul sebaiknya memanfaatkan secara optimal teknologi informasi (jaringan internet, hardware dan software/aplikasi) sehingga dapat meningkatkan efektifitas dalam menjalankan pekerjaan.

3. Pemda Kabupaten Gunungkidul sebaiknya melakukan perbaikan atas kelemahan pada praktik pengendalian internal sehingga meminimalisir terjadinya kecurangan atau kesalahan dalam pengelolaan keuangan OPD.
Pemanfaatan Teknologi Informasi dan Sistem Pengendalian Internal terhadap Kualitas Laporan Keuangan Daerah (Studi Empiris pada SKPD 
Kota Depok)". Majalah IImiah UNIKOM. 15(2): 201-210.

Andini, D. dan Yusrawati. 2015. "Pengaruh Kompetensi Sumber Daya Manusia dan Penerapan Sistem Akuntansi Keuangan Daerah terhadap Kualitas Laporan Keuangan Daerah pada SKPD Kabupaten Empat Lawang Sumatera Selatan". Jurnal Ekonomi, Manajemen dan Akuntansi. 24(1): 6582.

As Syifa Nurillah. 2014. "Pengaruh Kompetensi Sumber Daya Manusia, Penerapan Sistem Akuntansi Keuangan Daerah (SAKD), Pemanfaatan Teknologi Informasi dan Sistem Pengendalian Intern terhadap Kualitas Laporan Keuangan Pemerintah Daerah (Studi Empiris pada SKPD Kota Depok)". Diponegoro Journa of Accounting. 3(2): 1-13.

Badan Pemeriksa Keuangan. 2018. Ikhtisar Hasil Pemeriksaan Semester 1 Tahun 2018. Melalui http://www.bpk.go.id. Diunduh tanggal 9 Oktober 2018.

Badan Pengawas Keuangan dan
Pembangungan Perwakilan D.I.
Yogyakarta. 2017. Laporan Hasil
Pengawasan atas Akuntabilitas
Keuangan Negara/Daerah Tahun
2017. Melalui http://www.bpkp.go.id.
Diunduh tanggal 4 Desember 2018.

Bastian, Indra. 2015. Akuntansi Sektor Publik:Suatu Pengantar. Jakarta : Erlangga.

Desy Sefri Yensi. 2014. "Pengaruh Kompetensi Sumber Daya Manusia, Penerapan Sistem Akuntansi Keuangan Daerah dan Sistem Pengendalian Intern (Internal Audit) terhadap Kualitas Laporan Keuangan Pemerintah Daerah (Studi Empiris pada SKPD Kabupaten Kuantan Sengingi)". JOM FEKON. 1 : 1-15.
Ghozali, Imam. 2018. Aplikasi Analisis Multivariate dengan Program IBM SPSS 25. Semarang : Badan Penerbit Universitas Diponegoro.

Inapty, M A F B A,.dan Martiningsih, S P. 2016. "Pengaruh Penerapan Standar Akuntansi Pemerintah, Kompetensi Aparatur dan Peran Audit Internal terhadap Kualitas Informasi Laporan Keuangan". Akuntabilitas: Jurnal IImu Akuntansi. 9(1): 27-42.

Mahaputra, I P U R., dan Putra, I W. 2014. "Analisis Faktor-faktor yang Mempengaruhi Kualitas Informasi Pelaporan Keuangan Pemerintah Daerah". E-Jurnal Akuntansi Universitas Udayana. 8(2): 230-244.

Mokoginta, N., Lambey, L., dan Pontoh, W. $2017 . \quad$ "Pengaruh Sistem Pengendalian Intern dan Sistem Akuntansi Keuangan Daerah terhadap Kualitas Laporan Keuangan Pemerintah". Jurnal Riset Akuntansi Going Concern. 12(2): 874-890.

Patra, A D A., Bustami, L., dan Hasriani. 2015. "Pengaruh Penerapan Sistem Akuntansi Keuangan Pemerintah Daerah terhadap Kualitas Laporan Keuangan Pemerintah Daerah". Jurnal Akuntansi. 2(1): 1-9.

Rahmawati, A., Mustika, I W., dan Eka, L H. 2018. "Pengaruh Penerapan Standar Akuntansi Pemerintah, Pemanfaatn Teknologi Informasi dan Sistem Pengendalian Intern terhadap Kualitas Laporan Keuangan SKPD Kota Tangerang Selatan". Jurna Ekonomi, Bisnis dan Akuntani (JEBA). 20(2): 817.

Reni Yendrawati. 2013. "Pengaruh Sistem Pengendalian Intern dan Kapasitas Sumber Daya Manusia terhadap Kualitas Informasi Laporan Keuangan dengan Faktor Eksternal sebagai 
Variabel Moderating". JAAI. 17(2): 166-175.

Republik Indonesia. Peraturan Menteri Dalam Negeri Nomor 59 Tahun 2007 tentang Pedoman Pengelolaan Keuangan Daerah.

Peraturan Menteri Dalam Negeri Nomor 2 Tahun 2013 tentang Pedoman Pengembangan Sistem Pendidikan dan Pelatihan Berbasis Kompetensi di Lingkungan Kementrian Dalam Negeri dan Pemerintahan Daerah.

Peraturan Pemerintah Nomor 71 Tahun 2010 tentang Standar Akuntansi Pemerintahan.

Peraturan Pemerintah Nomor 60 Tahun 2008 tentang Sistem Pengendalian Intern Pemerintah.

Setyowati, L., Isthika, W., dan Pratiwi, R D. 2016. "Faktor-faktor yang Mempengaruhi Kualitas Laporan Keuangan Pemerintah Daerah Kota Semarang". Kinerja. 20(2): 179-191.

Siwambudi, I G N., Yasa, G W., dan Badera, I D N. 2017. "Komitmen Organisasi Sebagai Pemoderasi Pengaruh Kompetensi SDM dan Sistem Pengendalian Intern pada Kualitas Laporan Keuangan". E-Jurnal Ekonomi dan Bisnis Universitas Udayana. 6(1) : 385-416.

Suci Rahmadani. 2015. "Pengaruh Kompetensi Sumber Daya Manusia, Sistem Akuntansi Keuangan Daerah, Pemanfaatan Teknologi Informasi dan Sistem Pengendalian Intern terhadap Kualitas Laporan Keuangan Pemerintah Daerah (Studi pada Satuan Kerja Perangakat Daerah Kabupaten Pasaman Barat)". Jom FEKON. 2(2): 1-15.

Surastiani, D P. dan Handayani, B D. 2015. "Analisis Faktor-faktor yang
Mempengaruhi Kualitas Informasi Laporan Keuangan Pemerintah Daerah". Jurnal Dinamika Akuntansi. 7(2): 139-149. 